\title{
Initiation and Persistence to Statin Treatment in Patients with Diabetes Receiving Glucose-Lowering Medications 1997- 2006
}

\author{
H. Dominguez ${ }^{1, *}$, T. K. Schramm ${ }^{2}$, M. L. Norgaard ${ }^{1}$, S.Z. Abildstrøm ${ }^{3,4}$, L. Kober ${ }^{2}$, C. Jørgensen ${ }^{1}$, \\ T.J. Guterbaum ${ }^{1}$, H.E. Poulsen ${ }^{5,6,7}$, C. Torp-Pedersen ${ }^{1,7}$ and G. H. Gislason ${ }^{1}$ \\ ${ }^{I}$ Cardiology dpt. and Lab. P, Research Unit, Gentofte Hospital, Copenhaguen University, Hellerup, Denmark \\ ${ }^{2}$ Department of Cardiology, Rigshospitalet. Copenhagen University, Denmark \\ ${ }^{3}$ Cardiovascular Research Unit, Department of Internal Medicine, Copenhagen University Hospital Glostrup, Glostrup, \\ Denmark \\ ${ }^{4}$ National Institute of Public Health, University of Southern Denmark, Copenhagen, Denmark \\ ${ }^{5}$ Laboratory of Clinical Pharmacology Q7642, Rigshospitalet, Copenhagen, Denmark \\ ${ }^{6}$ Department of Clinical Pharmacology, Bispebjerg Hospital, Copenhagen, Denmark \\ ${ }^{7}$ Faculty of Health Sciences, University of Copenhagen, Denmark
}

\begin{abstract}
Aims: Since 2001 guidelines recommend statin treatment in most patients with diabetes. We investigated secular changes in initiation and persistence to statin treatment during a 10-year period in a nationwide cohort of patients initiating glucose-lowering medication (GLM).

Methods: All Danish citizens 30 years and older who claimed prescriptions of GLM between 1997 and 2006 were identified from nationwide registers of drug dispensing from pharmacies and hospitalizations, and followed until 2006. Statin treatment was registered if a prescription was claimed during the period. By logistic regression we analyzed factors related to initiation and persistence to statin treatment.

Results: In total 128,106 patients were included. In 1997 only $7 \%$ of the patients receiving GLM claimed statins within the first year after GLM initiation. Despite increasing statin prescriptions the following years, only $62 \%$ were using statins at the end of follow up. The chance of ever receiving statins was lowest if not initiated within 180-days following the first purchase of GLM (OR 0.75, 95\% CI 0.74-0.76). A previous myocardial infarction was associated with increased statin treatment (OR 4.51; 95\% CI 4.31 - 4.71), while low income was associated with lower use of statins (OR 0.68; $95 \% \mathrm{CI}$ 0.66-0.72). Between 75-85\% of the patients who initiated statins treatment were persistent to treatment by 2007.

Conclusions: In spite of increasing use of statins in diabetes patients over time, many patients remain untreated. Early initiation of statin treatment in diabetic patients and focus on patients with low socioeconomic status is needed to give long-term benefits.
\end{abstract}

Keywords: Diabetes, Statins, compliance, epidemiology, lipids

\section{INTRODUCTION}

The benefit of statin treatment in the diabetes population is well established [1-7]. American and European guidelines recommend lipid lowering therapy in diabetes patients because they consider diabetes as a cardiovascular risk equivalent to established coronary disease since 2001 [8-10]. Nevertheless, several cohort studies have observed an insufficient use of statins in target populations [11-13].

An underuse of recommended treatment can be related to several factors; i.e. lack of initiation of treatment, or due to

*Address correspondence to this author at the Cardiology department and Lab. P - Research Unit - Internal Post 163, Gentofte Hospital, Copenhaguen University, DK-2900 Hellerup, Denmark; Tel: +45 229893 43;

E-mail: hd@heart.dk interruption of treatment by the patient or in relation to concurrent medical or socioeconomic causes. Hence, it is important to identify which of these factors may be modified to improve adherence to treatment.

The aim of this study was to elucidate the extent of statins use over the last 10-years in the diabetic population in Denmark. The study included all Danish citizens receiving glucose-lowering medicine (GLM) and evaluated initiation and persistence to statin treatment in a 10 -year period.

\section{METHODS}

All claimed prescriptions from pharmacies in Denmark have been registered in the Danish Registry of Medicinal Products Statistics since 1995. All drugs are classified according to an international classification of drugs, the 
Anatomical Therapeutical Chemical (ATC) system, and the registry also includes information of date of dispensing, dosage, quantity dispensed and the affiliation of the physician issuing the prescription. All residents in Denmark are assigned a unique and permanent personal civil registration number which enables cross-linking between nationwide administrative registers at individual level, including data on residence and household income [14].

The Danish National patient Registry keeps records on all hospital admissions since 1978. Each admission is registered with 1 primary diagnosis, and if appropriate 1 and more secondary diagnoses, according to the International Classification of Diseases, the $8^{\text {th }}$ revision until 1994 (ICD8 ) and the $10^{\text {th }}$ revision (ICD-10) from 1994 [15].

The study cohort comprised all persons who claimed a prescription of GLM for the first time between 1997 and 2006. First time purchase of GLM was used as a proxy for newly diagnosed type 2 diabetes. To identify first time users of GLM, patients who had purchased a GLM before 1997 were excluded from the study.

Use of statins was followed until the end of 2007.

Statins can not be purchased over the counter in Denmark and we identified whether a statin was prescribed within 30 days from the first GLM purchased in each period and defined those as patients receiving statin at start of GLM. Similarly we identified patients receiving a statin within 180 days and 1 year from the first GLM prescription in each period, respectively, to identify patients with later initiation of statin treatment. Since treatment policies have changed throughout this period, the study period was divided in 4 intervals, where the last period corresponds to 2006. We calculated the period of days covered by a purchase of a statin based on the pack size, and assuming an average dose of 1 daily tablet.

\section{STATISTICAL ANALYSIS}

To analyze factors determining early initiation of statin treatment and initiation within 180 days after commencing
GLM we performed a multivariable logistic regression analysis. The regression analysis was adjusted for year of first GLM prescription claim (with 1997 as reference), age, sex, previous myocardial infarction (MI), insulin treatment as the first anti-diabetes medicine and income.

Income was graded in quartiles according to gross household income, obtained from administrative registers how was income data obtained?. Patients who had been hospitalized with a MI as primary diagnosis (ICD codes I21 or I22 and ICD- 8 code 410 for MI before 1994) in the 19-year period before inclusion were identified as "previous MI". Occurrence of MI during the study period was included as co-morbidity of interest.

Previous studies have demonstrated the importance of long-term adherence to statin treatment to optimize survival rates $[16,17]$. Adherence can be defined in different ways, most often it has been defined as the time-course until treatment is paused, but we have shown in a previous study from our group, that many patients who pause their medication after a MI do restart the treatment even after several months cessation[18]. For this reason we performed 2 analyses. One approach was a calculation of the percentage of patients who were receiving statins at any time-point and in another analysis the time until a break in treatment of 30 or 90 days was estimated. This approach has been described in details previously [18].

Multivariable Cox regression analysis was used to identify risk factors for a poor adherence to statin treatment.

\section{RESULTS}

In total, 5.6 million statin prescriptions were recorded for the entire period, from January 1, 1997 to December 31, 2006 and of those, 1.4 million were purchased by 128,106 patients who had a previous GLM prescription.

In the time period 1997 - 1999 only $3.6 \%$ of patients who initiated GLM treatment also claimed statins within 30 days subsequently to GLM purchase (Table 1) increasing to

Table 1. Basal Characteristics for Patients Starting Statins after Commencing Glucose-Lowering Medications (GLM) in Denmark in the Period 1997-2006

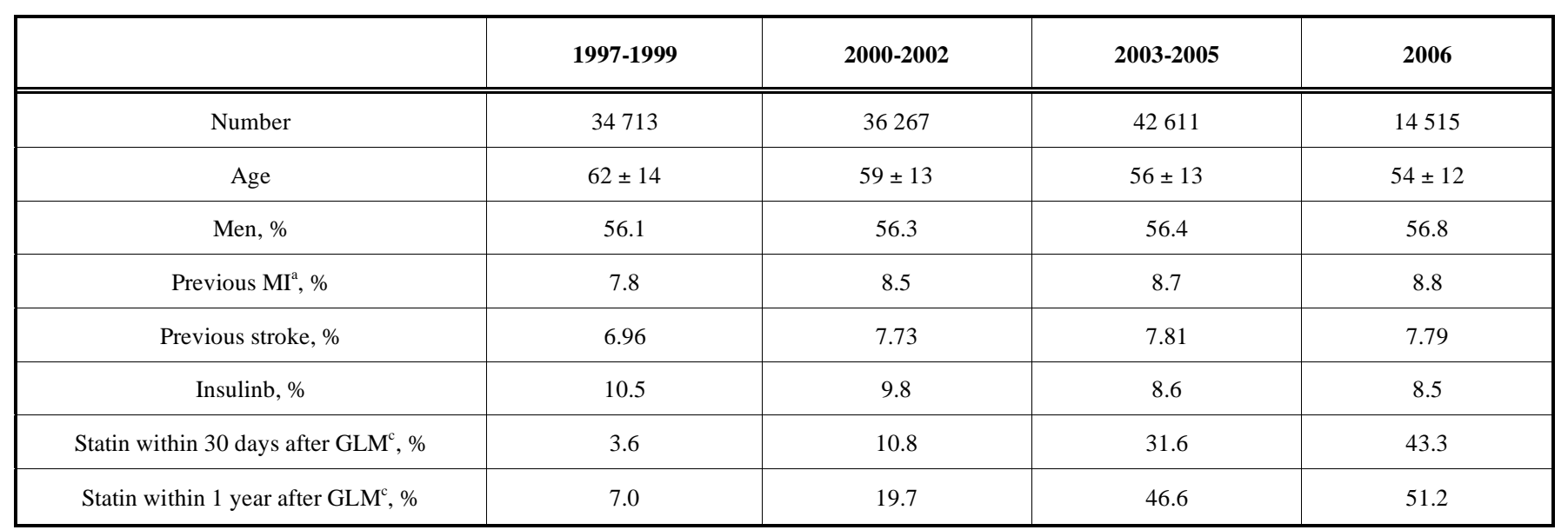

${ }^{a}$ Previous acute myocardial infarction (MI) is considered when patients had a previous hospitalization with the diagnosis of a MI by the first claim of GLM.

${ }^{\mathrm{b}}$ Insulin refers to the proportion of patients taking insulin at the beginning of each observation period.

${ }^{c}$ Purchase of statins is shown as the proportion of patients who were dispensed statins latest 30 days after their first GLM purchase or within 1 year after their first GLM purchase, respectively. 
$43.3 \%$ in 2006. The fraction of patients initiating statin treatment later than 30 days at any time after start of GLM increased only moderately (less than $5 \%$ per year), and no more than $62 \%$ of patients using GLM in total received statin treatment by the end of the study (Fig. 1). About $8 \%$ and $7 \%$ of the patients who claimed GLM had a previous MI and a previous stroke diagnosis, respectively. These numbers were constant throughout the observation period (Table 1).

The proportion of patients who claimed insulin as their first GLM during 1997 was 10.5\%. This proportion decreased slightly in the following years (Table 1). Furthermore, persons using GLM were progressively younger throughout the study period.

Among all patients receiving GLM, 12146 had suffered a MI and 10886 a stroke. Table 2 shows the results of the multivariable logistic regression analysis on factors influencing initiation of statin treatment within 180 days from first prescription of GLM. Older patients were less likely to receive statins, with a reduction in OR decrease by $11 \%$ for each 10-year increase in age. The chance that patients claimed statins after commencing GLM increased over the years, accordant with the inclinations of the curves depicted in Fig. (1). Furthermore, a previous MI was among the strongest predictors for initiation of statin treatment, OR 4.51 (95\% CI $4.31-4.71)$ while patients with a previous stroke were less likely to receive statins (OR 0.39 (95\% CI 0.32 0.42). Patients who were started on insulin as first GLM had a reduced likelihood of receiving statins with an OR of 0.54 (95\% CI $0.51-0.57)$. Age did not appear to influence the use of statins in patients started on insulin since it was not possible to identify a statistical interaction $(\mathrm{p}=0.12)$.

Table 3 shows an analysis on which factors determined a patient's likelihood of receiving statins more than 3 months after commencing GLM. Use of insulin as the first GLM medication decreased the odds for commencing statins within the following year by $50 \%$, while a previous MI markedly increased the chance of statins being prescribed within one year after the first claim of GLM.

Once commencing treatment with statins, patients maintained the treatment throughout the following years (Fig. 2). Most brakes in statin treatment occurred soon after initiation, but most patients restarted the treatment and more than $80 \%$ continued statin treatment in the following years (Fig. 2). We further analyzed elapsed time from the first statin prescription until the treatment was withheld for 30 and 90-days, respectively. This analysis confirms a high adherence to the treatment. More than 3 years elapsed before the treatment was withheld for 30 days in $50 \%$ of the population and nearly 10 years before it was withheld for 90 -days in $50 \%$ of the population (Fig. 3).

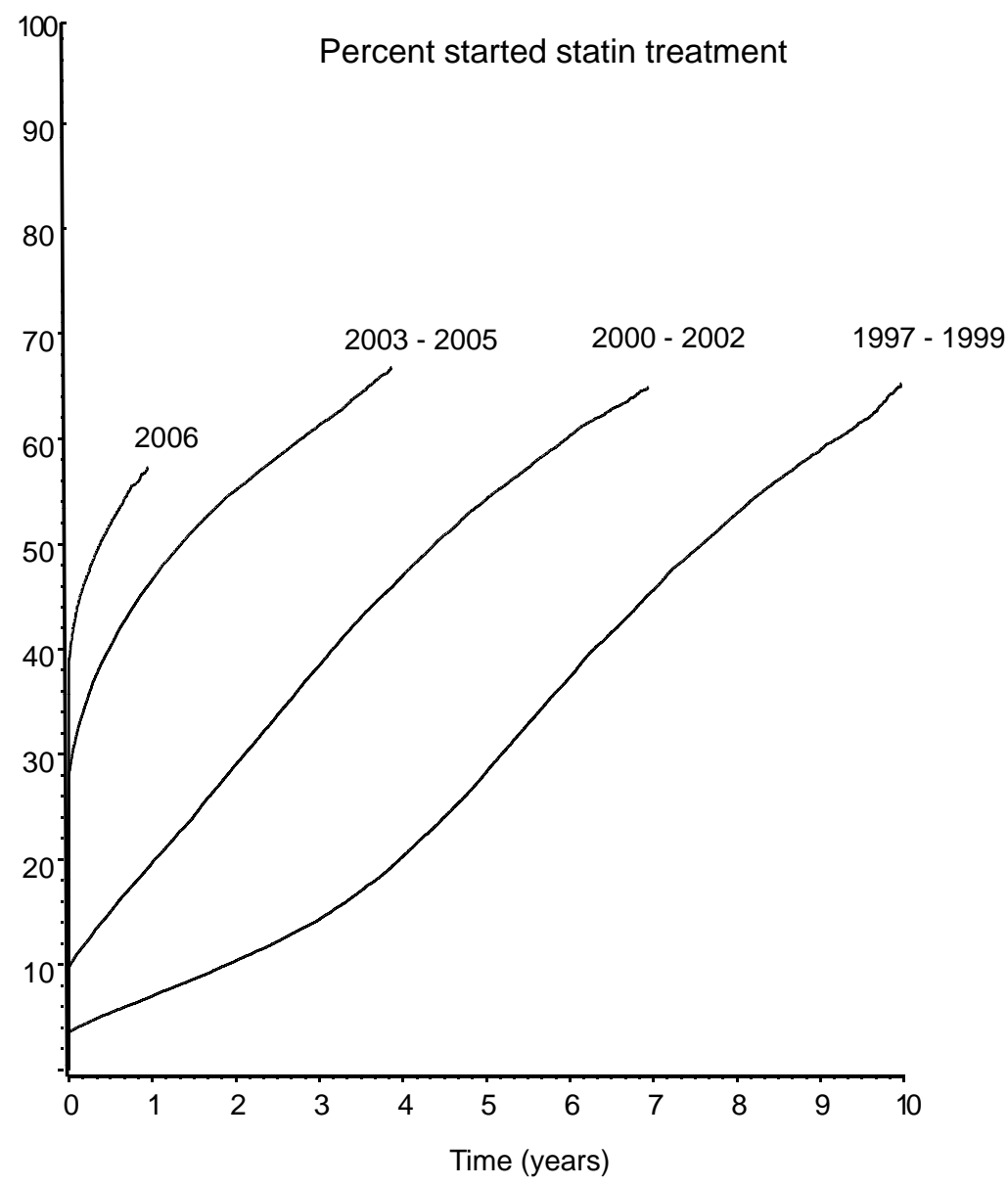

Fig. (1). Cumulative frequency of patients who claimed a statin prescription after their first glucose-lowering medication purchase. 
Table 2. Logistic Regression of Covariates Related to Start of Statin Treatment within 180 Days after the First Purchase of Glucose-Lowering Medicine

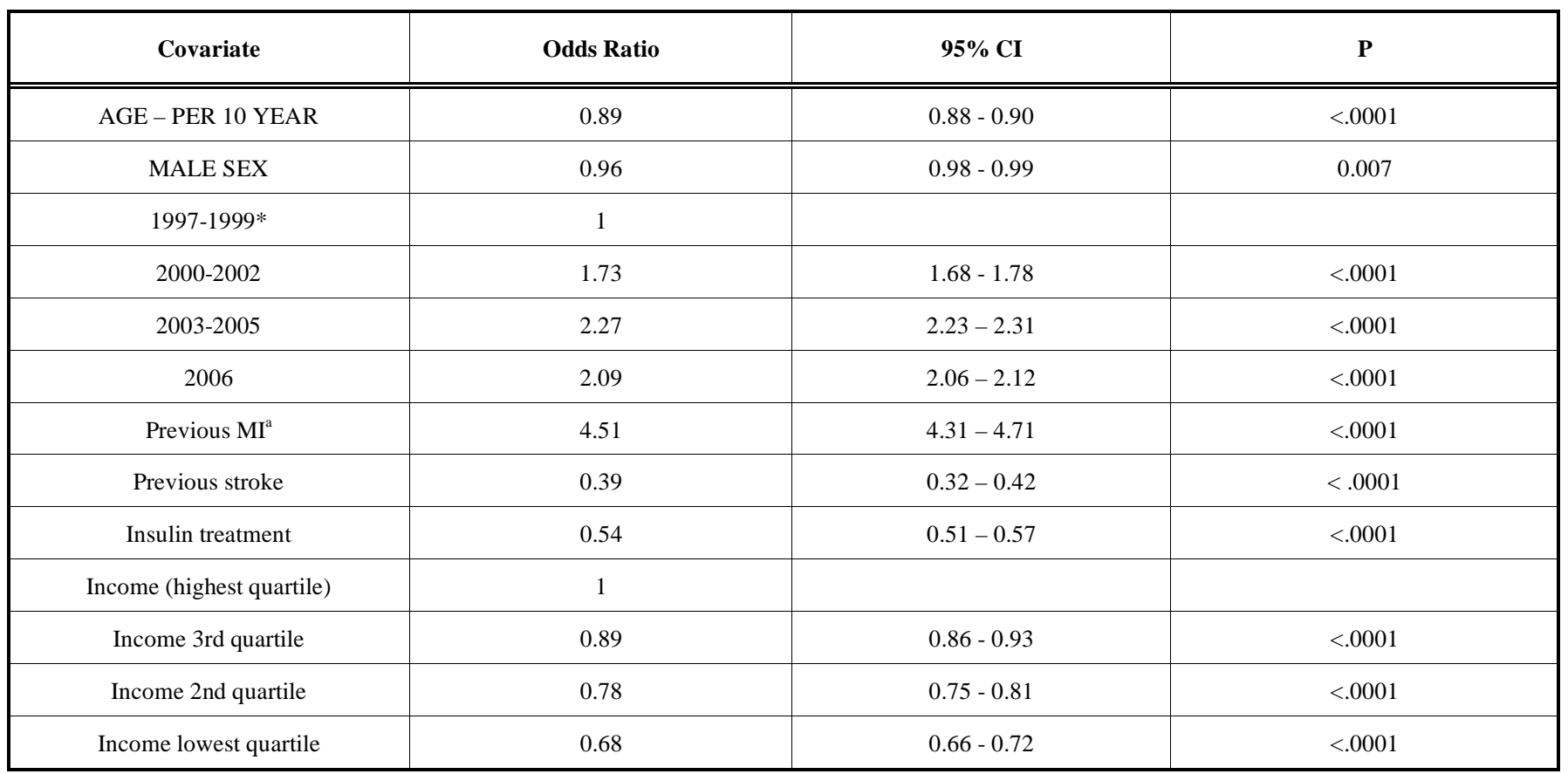

${ }^{\mathrm{a}} \mathrm{MI}$ is myocardial infarction; * reference in logistic regression analysis.

Table 3. Logistic Regression of Factors Related to Start of Statin Treatment Later than 180 Days after the First Purchase of Glucose-Lowering Medicine

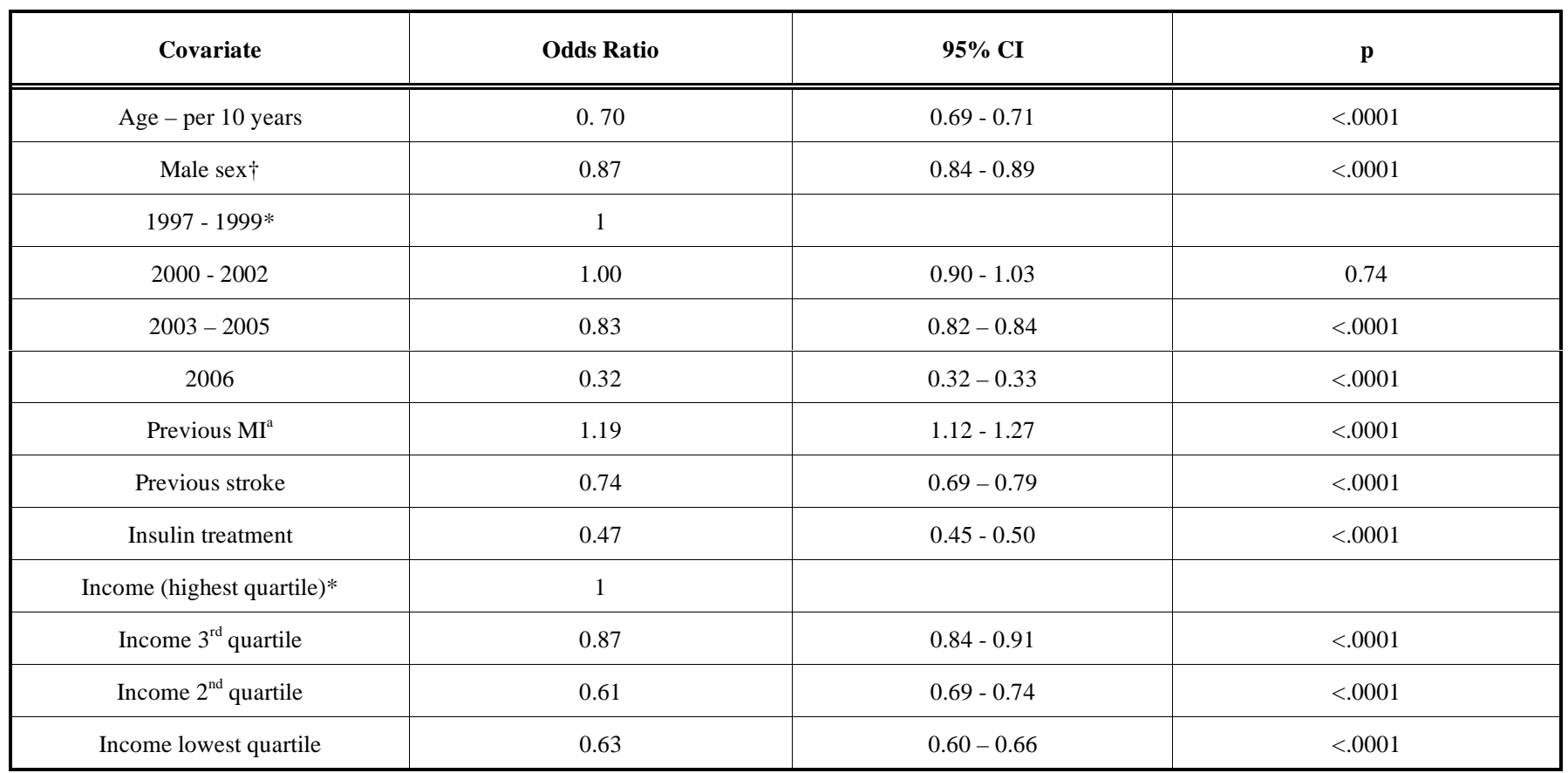

${ }^{\mathrm{a}} \mathrm{MI}$ is myocardial infarction; *reference in logistic regression analysis. $\dagger$ Women as reference.

To elucidate which factors determined a poor long-term persistence (break in treatment of 90 days), we performed a multivariable Cox regression analysis (Table 4). This analysis shows that men had a poorer persistence to treatment than women, and that patients with previous MI and elderly had higher persistence to treatment. Furthermore, we found a linear gradient of increasing risk associated with lower income. An equivalent Cox regression analysis for the period 1997 to 2004 found a much stronger association of poor adherence with lower income, with a HR 1.98 (CI $1.82-2.16$, $\mathrm{p}<0.001$ ) for the 2nd quartile and 2.11 (CI $1.62-2.75$, $\mathrm{p}<$ 0.002 ) for the lowest quartile. 


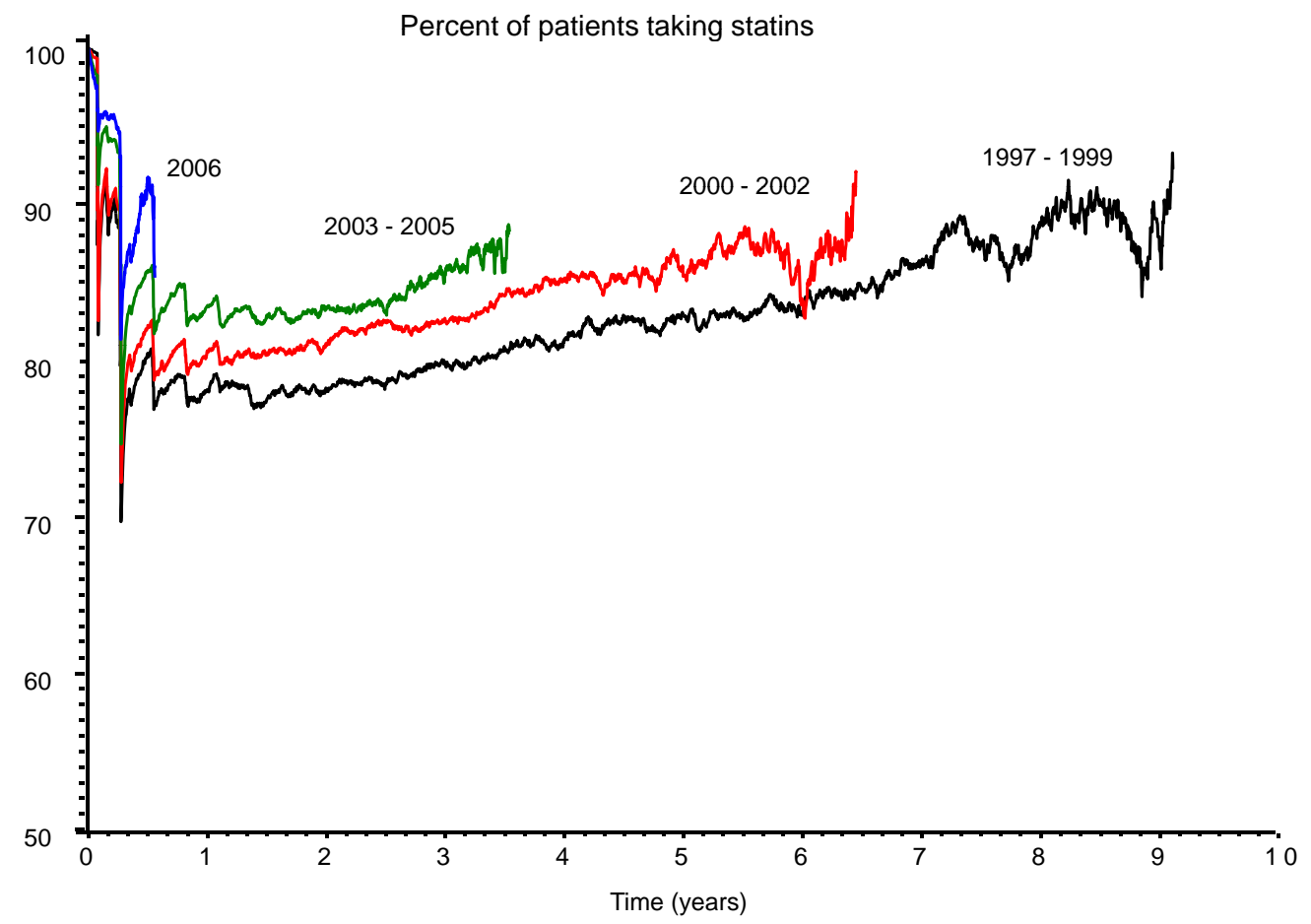

Fig. (2). Proportion of patients receiving glucose lowering medication who were taking statins at any time-point since the first statin purchase, according to treatment period.

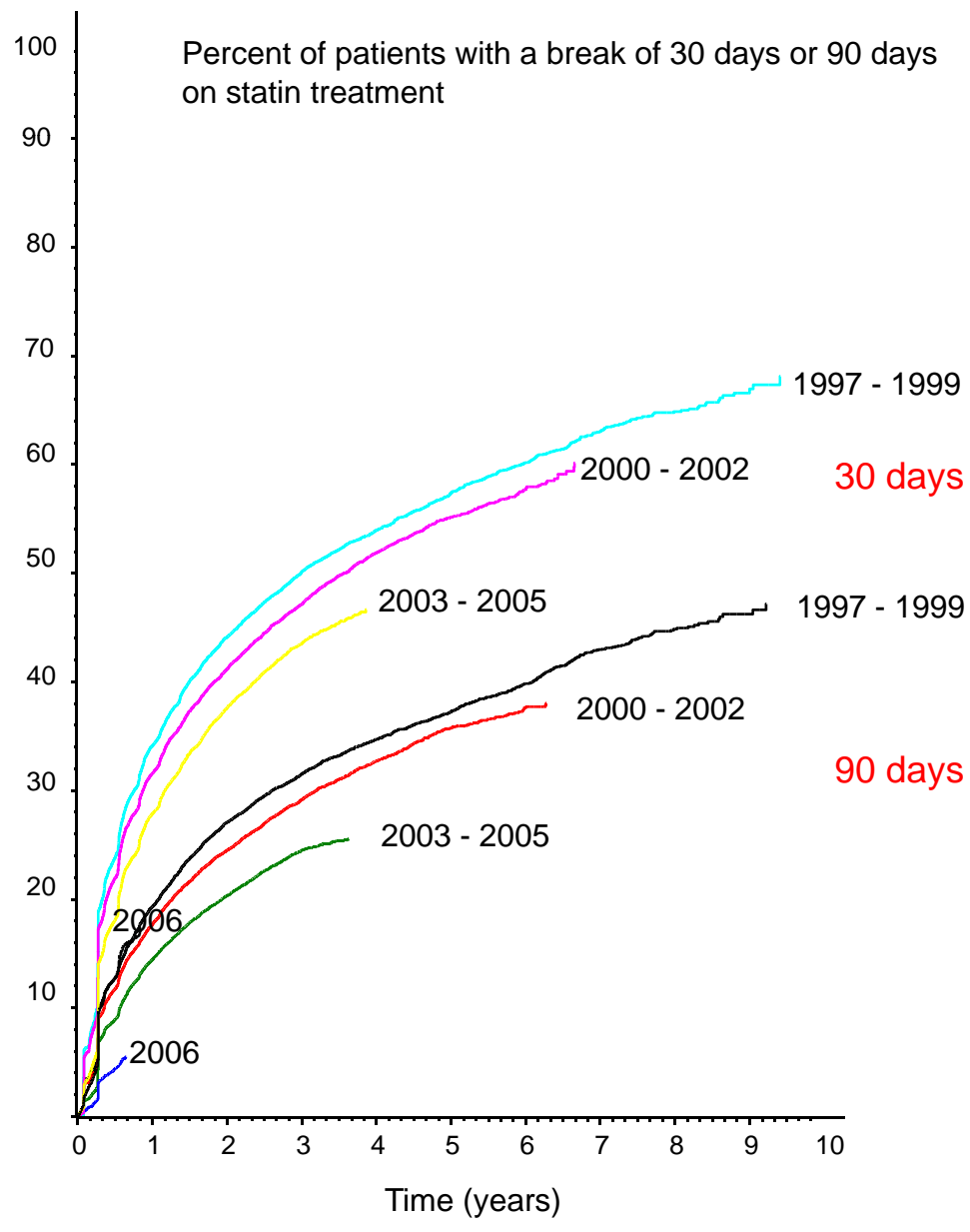

Fig. (3). Elapsed time from the first statin purchase to a break in treatment of 30-days and a 90-days, respectively, according to period of treatment initiation. 
Table 4. Cox Proportional-Hazard Analysis of Covariates Influencing Poor Adherence to Statin Treatment (Break in Treatment of 90 Days) in Patients Receiving Glucose Lowering Medication

\begin{tabular}{|c|c|c|c|}
\hline Covariates & Hazard Ratio & $\mathbf{9 5 \%}$ CI & p \\
\hline \hline Age - per 10 years & 0.85 & $1.11-1.19$ & $<.0001$ \\
\hline Male sex & 1.15 & & $<.0001$ \\
\hline $1997-1999$ & 1 & $0.94-0.97$ & $<.0001$ \\
\hline $2000-2002$ & 0.95 & $0.88-0.90$ & $<.0001$ \\
\hline $2003-2005$ & 0.89 & $0.75-0.76$ & $<.0001$ \\
\hline 2006 & 0.74 & $0.75-0.85$ & $<.0001$ \\
\hline Previous MI & 0.80 & $0.84-0.98$ & 0.009 \\
\hline Previous stroke & 0.91 & $0.85-0.97$ & 0.005 \\
\hline Insulin treatment & 0.91 & 1.07 & 0.11 \\
\hline Income (highest quartile) & 1.03 & $0.98-1.84$ & 0.002 \\
\hline Income $3^{\text {rd }}$ quartile & 1.07 & $1.03-1.15$ & 0.002 \\
\hline Income 2 ${ }^{\text {nd }}$ quartile & 1.09 & & \\
\hline Income lowest quartile & & & \\
\hline
\end{tabular}

${ }^{\mathrm{a}} \mathrm{MI}$ is myocardial infarction.

The first prescription was initiated by the general practitioner in $91 \%$ of the cases. Accordingly, only $26 \%$ of the patients had a hospital admission in a 60-days period preceding the purchase of the first statin prescription. Hence, a majority of hospitalized patients were discharged without a statin prescription.

\section{DISCUSSION}

This is a nationwide study on the use of statins in patients initiating GLM in the period after 1997. In spite of an increasing initiation of statin treatment along with start of GLM, by the end of 2006, only $51 \%$ of the patients purchasing GLM during the last observation year received statins. The tendency towards increasing statin initiation occurred slowly over the years. At the end of follow-up only $62 \%$ of the patients receiving GLM were treated with statins while, according to international guidelines from 2001[8], almost $100 \%$ of them should receive statins (Fig. 1).

Donelly et al. found that the poorest long-term adherence to statins in patients with diabetes occurred among younger patients, especially among those without cardiovascular disease[19], which is consistent with our observations. In accordance with Donelly's and other studies, the presence of a previous MI increased the chance of receiving a statin in the diabetic population compared with patients without established coronary heart disease [19-21]. Nevertheless, there is still room for improvement in the use of statin in patients with coronary heart disease both in Denmark [22, 23] and in European countries in general [24], especially taking into account that the cardiovascular risk in the diabetic population is equivalent to that of the patients with a previous MI [25].

We found a linear gradient in decreased initiation of statin treatment according to socioeconomic status. This is an important observation that requires further attention. Previous studies, in Denmark and abroad, have demonstrated lower use of statins in coronary patients with lower socioeconomic status [23, 26-28]. In Denmark all citizens receive partial reimbursement by the government financed health security system, independent of employment status, income, age or participation in private health insurance systems. The policies regulating partial reimbursement have changed several times during the study. One of these policy changes carried a substantial reimbursement increase after 2002. Interestingly, the most remarkable change in the pattern for early use of statins occurs from the period 2000-2002 to the period 2003-2005 (Fig. 1), which may be associated with the change of policies in 2002, although there were other factors that may have influenced this evolution, such as international guidelines from 2001 recommending intensive lipid lowering in all diabetic patients[8]. In this context it is interesting that that the HR associated with lower income for the period 1997-2004 were substantially higher than the HR for the entire period (Table 4), suggesting that income became less important for an adequate persistence to statins in the later years. These results altogether point to medicine pricing as a major factor for poorer adherence to statin treatment among patients with low socioeconomic status.

The reduced odds for receiving statins in patients commencing on insulin as first GLM may be due to inclusion of patients with type 1 diabetes. Treatment with GLM and statins were generally initiated at general practices, reflecting the general practitioner's important role in secondary prevention. This study demonstrates the need for focus on secondary prevention after discharge for what condition?, since only a minority of patients receiving GLM after discharge subsequently initiated statin treatment. This is worrying and reflects low awareness on the subject among hospital physicians caring for diabetic patients. Even though the study ac- 
counts for any cause of hospitalization, it is important to emphasize the importance of prescription of statins in diabetic patients shortly after hospitalization for acute coronary syndromes, as this leads to a higher adherence to statins [18]. Furthermore, prescription of statins shortly after hospitalization has been demonstrated to improve their outcomes in clinical trials [29, 30], as well as in patients hospitalized with MI [27]. An increased prescription of statins shortly after diagnosis of type 2 diabetes has improved the outcome in the general population in U.K. [31].

Given these difficulties with low adherence to statin treatment it is important to consider possible improving strategies. Several adherence programs in U.S. have been successful $[32,33]$. One of them was based on claimed prescriptions to identify prescribers as well as target patients, where prescribers were warned when their patients were not receiving statins. This approach improved adherence to statins and was cost-effective [32]. In another successful program, patients with diabetes received individualized telephonic counseling [33]. Identification of target patients based on claimed prescriptions and hospitalization diagnosis is feasible in Denmark and in other countries where prescriptions are registered. Once identified it is possible to contact the patients as well as their primary care doctors. In most European countries this is a possible national approach.

This study has several limitations that are important to emphasize. We lack information about additional factors influencing the decision for initiation of statin treatment, the most important one being individual patient lipid levels. However, guidelines recommend low target lipid levels in all diabetic patients $[8,10,34]$, and most patients do not reach those targets without pharmaceutical intervention. Thus, statin treatment is indicated for most diabetes patients. Another limitation is that we do not have information about patients that were intolerant to treatment or terminated treatment due to side-effects. Nor do we have information on patients with contraindications to treatment with statins. $\mathrm{Pa}$ tients with diabetes not taking GLM were not included in the study; therefore it is not possible to conclude on how extensive the use of statins is in these patients. The exclusion of patients who had claimed GLM before 1997 does not warrant that patients who claimed GLM in 1997 and later on did so for the very first time. Some of these patients may have started GLM treatment earlier but through dieting and exercise they might have achieved control of glycaemia and thereby, delayed the need for restarting GLM until further development of diabetes. Furthermore, in our study it is not possible to identify type 1 and type 2 diabetes among insulin consumers. Finally, our study did only identify prescription claims of statins, the predominant type of lipid lowering medication, but did not identify use of other types of lipid lowering drugs. How many patients were on fibrates or other lipid lowering drugs?

The criteria for the diagnosis of MI have changed through the observation period. The diagnosis of MI in the National Patient Registry has proved to be valid, with a sensitivity of $91 \%$ and a positive predictive value of $93 \%$ [35].

The main strength of the study is the completeness of data, including all diabetes patients receiving GLM treatment on nationwide level in Denmark. The main advantage of using GLM to identify diabetic patients is that the indication for treatment is specific for diabetes.

\section{CONCLUSIONS}

Use of statins in the diabetic population receiving GLM in Denmark is insufficient. Older age predicts low initiation and low income predicts both low initiation and low persistence. Once started, patients continue taking statins. For long-term benefits, focus should be based on improvement of initiation of statin treatment in patients with diabetes. Efforts on improvement of the use of statins in patients receiving GLM should be focused on general practitioners, especially in relation to diagnosis of diabetes, as well as systematically securing that hospitalized patients receive adequate prescription at discharge.

\section{ABBREVIATIONS}

$\begin{array}{lll}\text { ATC } & =\text { Anatomical Therapeutical Chemical } \\ \text { GLM } & =\text { Glucose Lowering Medications } \\ \text { ICD } & =\text { International Classification of Diseases } \\ \text { MI } & =\text { Myocardial Infarction }\end{array}$

\section{CONFLICT OF INTEREST}

None of the authors have conflicts of interest to disclose.

\section{ACKNOWLEDGEMENTS}

This study has been performed with funding from The Danish Ministry of Interior and Health. Compliance Funding j.nr.: 2006-13009-315 and from The Danish Agency for Science, Technology and Innovation (Grant no. 271-080944)

\section{REFERENCES}

[1] MRC/BHF Heart Protection Study of cholesterol lowering with simvastatin in 20,536 high-risk individuals: a randomised placebocontrolled trial. Lancet 2002; 360: 7-22.

[2] Colhoun HM, Betteridge DJ, Durrington PN, et al. Primary prevention of cardiovascular disease with atorvastatin in type 2 diabetes in the Collaborative Atorvastatin Diabetes Study (CARDS): multicentre randomised placebo-controlled trial. Lancet 2004; 364: 685-96.

[3] Sever PS, Poulter NR, Dahlof B, et al. Reduction in cardiovascular events with atorvastatin in 2,532 patients with type 2 diabetes: Anglo-Scandinavian Cardiac Outcomes Trial--lipid-lowering arm (ASCOT-LLA). Diabetes Care 2005; 28: 1151-7.

[4] Athyros VG, Papageorgiou AA, Symeonidis AN, et al. Early benefit from structured care with atorvastatin in patients with coronary heart disease and diabetes mellitus. Angiology 2003; 54: 67990.

[5] Shepherd J, Barter P, Carmena R, et al. Effect of lowering LDL cholesterol substantially below currently recommended levels in patients with coronary heart disease and diabetes: the Treating to New Targets (TNT) study. Diabetes Care 2006; 29: 1220-6.

[6] Ahmed S, Cannon CP, Murphy SA, Braunwald E. Acute coronary syndromes and diabetes: Is intensive lipid lowering beneficial? Results of the PROVE IT-TIMI 22 trial. Eur Heart J 2006; 27: 2323-9.

[7] Knopp RH, d'Emden M, Smilde JG, Pocock SJ. Efficacy and safety of atorvastatin in the prevention of cardiovascular end points in subjects with type 2 diabetes: the Atorvastatin Study for Prevention of Coronary Heart Disease Endpoints in non-insulin-dependent diabetes mellitus (ASPEN). Diabetes Care 2006; 29:1478-85.

[8] Executive Summary of The Third Report of The National Cholesterol Education Program (NCEP) Expert Panel on Detection, Evaluation, And Treatment of High Blood Cholesterol In Adults (Adult Treatment Panel III). JAMA 2001; 285: 2486-97. 
[9] Buse JB, Bigger JT, Byington RP, et al. Action to Control Cardiovascular Risk in Diabetes (ACCORD) trial: design and methods. Am J Cardiol 2007; 99: 21i-33i.

[10] Ryden L, Standl E, Bartnik M, et al. Guidelines on diabetes, prediabetes, and cardiovascular diseases: executive summary. The Task Force on Diabetes and Cardiovascular Diseases of the European Society of Cardiology (ESC) and of the European Association for the Study of Diabetes (EASD). Eur Heart J 2007; 28: 88-136.

[11] Jackevicius CA, Mamdani M, Tu JV. Adherence with statin therapy in elderly patients with and without acute coronary syndromes. JAMA 2002; 288: 462-7.

[12] Benner JS, Glynn RJ, Mogun H, et al. Long-term persistence in use of statin therapy in elderly patients. JAMA 2002; 288: 455-61.

[13] Avorn J, Monette J, Lacour A, et al. Persistence of use of lipidlowering medications: a cross-national study. JAMA 1998; 279: 1458-62.

[14] WHO. The WHO Collaborating Centre for Drug Statistiscs Methodology. ATC index with DDDs and Guidelines for ATC classification and DDD assignment. Oslo. 2007.

[15] WHO. International Statistical Classification og Diseases and Related Health Problems 2004; p. 2.

[16] Allen Maycock CA, Muhlestein JB, Horne BD, et al. Statin therapy is associated with reduced mortality across all age groups of individuals with significant coronary disease, including very elderly patients. J Am Coll Cardiol 2002; 40: 1777-85.

[17] Larsen J, Andersen M, Kragstrup J, Gram LF. High persistence of statin use in a Danish population: compliance study 1993-1998. Br J Clin Pharmacol 2002; 53: 375-8.

[18] Gislason GH, Rasmussen JN, Abildstrom SZ, et al. Long-term compliance with beta-blockers, angiotensin-converting enzyme inhibitors, and statins after acute myocardial infarction. Eur Heart J 2006; 27: 1153-8.

[19] Donnelly LA, Doney AS, Morris AD, Palmer CN, Donnan PT. Long-term adherence to statin treatment in diabetes. Diabetes Med 2008; $25: 850-5$

[20] Lee VW, Ho IC, Chan WS, Tam KY, Lee KK. Statin utilization patterns for the primary prevention of cardiovascular events: a retrospective study in patients with diabetes mellitus in Hong Kong. Am J Cardiovasc Drugs 2008; 8: 199-205.

[21] Jotkowitz AB, Novack V, Rabinowitz G, Segal AR, Weitzman R, Porath A. A national study on lipid management. Eur J Intern Med 2008; 19: 356-61.

[22] Rasmussen JN, Gislason GH, Abildstrom SZ, et al. Statin use after acute myocardial infarction: a nationwide study in Denmark. Br J Clin Pharmacol 2005; 60: 150-8.

[23] Rasmussen JN, Gislason GH, Rasmussen S, et al. Use of statins and beta-blockers after acute myocardial infarction according to income and education. J Epidemiol Commun Health 2007; 61: $1091-7$.
[24] Kotseva K, Stagmo M, De Bacquer D, De Backer G, Wood D; EUROASPIRE II Study Group. Treatment potential for cholesterol management in patients with coronary heart disease in 15 European countries: findings from the EUROASPIRE II survey. Atherosclerosis 2008; 197: 710-7.

[25] Schramm TK, Gislason GH, Kober L, et al. Diabetes patients requiring glucose-lowering therapy and nondiabetics with a prior myocardial infarction carry the same cardiovascular risk: a population study of 3.3 million people. Circulation 2008; 117: 1945-54.

[26] Schneeweiss S, Patrick AR, Maclure M, Dormuth CR, Glynn RJ. Adherence to statin therapy under drug cost sharing in patients with and without acute myocardial infarction: a population-based natural experiment. Circulation 2007; 115: 2128-35.

[27] Jackevicius CA, Li P, Tu JV. Prevalence, predictors, and outcomes of primary nonadherence after acute myocardial infarction. Circulation 2008; 117: 1028-36.

[28] Manderbacka K, Keskimaki I, Reunanen A, Klaukka T. Equity in the use of antithrombotic drugs, beta-blockers and statins among Finnish coronary patients. Int J Equity Health 2008; 7: 16.

[29] Schwartz GG, Olsson AG, Ezekowitz MD, et al. Effects of atorvastatin on early recurrent ischemic events in acute coronary syndromes: the MIRACL study: a randomized controlled trial. JAMA 2001; 285: 1711-8.

[30] de Lemos JA, Blazing MA, Wiviott SD, et al. Early intensive vs a delayed conservative simvastatin strategy in patients with acute coronary syndromes: phase Z of the A to Z trial. JAMA 2004; 292: 1307-16.

[31] Charlton J, Latinovic R, Gulliford MC. Explaining the decline in early mortality in men and women with type 2 diabetes: a population-based cohort study. Diabetes Care 2008; 31: 1761-6.

[32] Stockl KM, Tjioe D, Gong S, Stroup J, Harada AS, Lew HC. Effect of an intervention to increase statin use in medicare members who qualified for a medication therapy management program. J Manag Care Pharm 2008; 14: 532-40.

[33] Thiebaud P, Demand M, Wolf SA, Alipuria LL, Ye Q, Gutierrez PR. Impact of disease management on utilization and adherence with drugs and tests: the case of diabetes treatment in the Florida: a Healthy State (FAHS) program. Diabetes Care 2008; 31: 171722.

[34] Buse JB, Ginsberg HN, Bakris GL, et al. Primary prevention of cardiovascular diseases in people with diabetes mellitus: a scientific statement from the American Heart Association and the American Diabetes Association. Circulation 2007; 115: 114-26.

[35] Madsen M, Davidsen M, Rasmussen S, Abildstrom SZ, Osler M. The validity of the diagnosis of acute myocardial infarction in routine statistics: a comparison of mortality and hospital discharge data with the Danish MONICA registry. J Clin Epidemiol 2003; 56: $124-30$.

This is an open access article licensed under the terms of the Creative Commons Attribution Non-Commercial License (http://creativecommons.org/licenses/ by-nc/3.0/) which permits unrestricted, non-commercial use, distribution and reproduction in any medium, provided the work is properly cited. 